\title{
LITERATURA, LITERATURA COMPARADA, TRADUCCIÓN, ANALOGÍA ${ }^{*}$
}

\author{
LITERATURE, COMPARATIVE LITERATURE, \\ TRANSLATION, ANALOGY
}

Tomás Albaladejo

Universidad Autónoma de Madrid

\section{ABSTRACT}

This paper deals with the relationship between literature and translation. Literary translation is explained taking into account its similarities and differences with non-literary translation, and it is connected with the kinds of texts, in such a way that the target text reproduces the literariness of the source text. The role of translator in interpreting a literary work and in achieving a translation of it is focused as one of the main components of the translator's function. The point of view provided by analogy is adopted to study the transformation of the source text into the target text and the representation of the former by the latter. Literary translation is considered to be an activity within comparative literature due to the comparative attitude and activity that the translator must have by comparing the target text with the source text or the translation achieved with other works and other translations.

${ }^{*}$ ) Este trabajo es resultado de investigación realizada en el proyecto de investigación «Analogía, equivalencia, polivalencia y transferibilidad como fundamentos retórico-culturales e interdiscursivos del arte de lenguaje: literatura, retórica, discurso» (Referencia PGC2018-093852-B-I00. Acrónimo: TRANSLATIO), financiado por el Ministerio de Ciencia e Innovación de España y por la Unión Europea. 
Because of the intercultural role of literary translation, its function in the construction of transnational spaces as well as in the shaping of the canon or canons is highly valued.

Key words: Literary translation, comparative literature, translation text, interculturality, analogy.

\section{RESUMEN}

Este artículo se ocupa de la relación entre literatura y traducción. Se explica la traducción literaria teniendo en cuenta sus semejanzas y diferencias con la traducción no literaria y se conecta aquella con las clases de textos, de modo que el texto de llegada reproduzca la literariedad del texto de partida. El papel del traductor o la traductora en la interpretación de una obra literaria y en el logro de una traducción de esta es enfocado como uno de los principales componentes de su función. Se adopta el punto de vista que proporciona la analogía para estudiar la transformación del texto de partida en el texto de llegada y la representación del primero por este último. Se considera la traducción literaria como una actividad en la literatura comparada debido a la actitud y la actividad comparativa que el traductor debe tener comparando el texto de llegada con el texto de partida o la traducción lograda con otras obras y otras traducciones. A causa del papel intercultural de la traducción literaria, su función en la construcción de espacios transnacionales, así como en la configuración del canon o los cánones, es altamente valorada.

Palabras clave: Traducción literaria, literatura comparada, texto traducción, interculturalidad, analogía.

Fecha de recepción: 2 de octubre de 2021.

Fecha de aceptación: 23 de diciembre de 2021.

Cómo citar: Albaladejo, Tomás (2021): «Literatura, literatura comparada, traducción, analogía», en Actio Nova: Revista de Teoría de la Literatura y Literatura Comparada, monográfico 5: $1-25$.

DOI: https://doi.org/10.15366/actionova2021.m5.001 


\section{TRADUCCIÓN, COMUNICACIÓN Y MEDIACIÓN.}

La traducción es una actividad de comunicación y, dentro de esta, de mediación. Es, por tanto, una forma de comunicación mediadora, ya que del proceso de traducción forman parte la interpretación de un texto de la lengua de partida (texto de partida, texto fuente o texto original) previamente existente y su transformación en un texto de la lengua de llegada, (texto de llegada, texto meta o texto traducción), que quien realiza la traducción comunica a unos receptores que pueden ser distintos de los del texto de la lengua de partida, aunque también pueden coincidir con estos. La traducción se caracteriza por la transformación y la transferencia (Albaladejo, 1998); la interpretación del traductor es transitiva: interpreta el texto que traduce y a partir de su interpretación crea un nuevo texto que comunica; se combinan de este modo en la traducción la interpretación y la creación, al haber una interpretación, la del texto origen, y una creación, la del texto meta. El traductor o la traductora ejerce de este modo una mediación entre el texto de partida, que ha sido producido previamente por su creador, y los receptores del texto traducción. De este modo está haciendo también una mediación entre el autor del texto de partida y los lectores del texto traducción. Gracias a esta mediación pueden acceder al texto original, a través de su traducción, receptores que, por desconocer la lengua en la que está dicho texto, la lengua de partida, o por no tener conocimientos suficientes de esta, no pueden leer el original o no pueden aprovechar al máximo su lectura intensificando su interpretación.

Tener en cuenta las tres clases de traducción planteadas por Jakobson contribuye a situar la traducción literaria en el campo de la mediación comunicativa textual Jakobson, 1974). La traducción intralingüística es aquella en la que la lengua de partida y la lengua de llegada son la misma lengua, es el caso de las paráfrasis y también de las versiones modernas de textos de fases anteriores de la lengua, como es el caso de «El brujo postergado» de Jorge Luis Borges, que reescribe en castellano del siglo xx el cuento «De lo que conteçió a un Deán de Sanctiago con don Yllán, el grant maestro de Toledo» de El conde Lucanor o Libro de Patronio del Infante don Juan Manuel. La traducción interlingüística es la que habitualmente se conoce como traducción sin ningún adjetivo, consiste en traducir un texto de una lengua a otra lengua distinta; es un ejemplo la traducción que Thomas Shelton hizo al inglés de las dos partes del Quijote de Miguel de Cervantes. La traducción intersemiótica es la transformación de un texto construido en un sistema de signos en un texto de un sistema de signos distinto, 
por ejemplo, la sinfonía Harold en Italie de Hector Berlioz es traducción intersemiótica del canto IV de la obra literaria Childe Harold's Pilgrimage de Lord Byron. Habitualmente, cuando nos referimos a la traducción literaria pensamos en que está situada en el ámbito de la traducción interlingüística, pero, si bien la gran mayoría de las traducciones literarias son interlingüísticas, es necesario tomar en consideración las traducciones intralingüísticas, como la antes mencionada de Borges o la versión moderna que Pedro Salinas hizo del Cantar de Mio Cid.

La comprensión de un texto, su interpretación, es una forma de traducir: «entender es traducir» según George Steiner (2001: 23 y ss.). La traducción como comprensión se produce entre diferentes lenguas, pero también dentro de una misma lengua:

La "traducción", entendida en el sentido apropiado, es un segmento especial del arco de la comunicación que todo acto verbal efectivo describe en el interior de una lengua determinada. Cuando están en juego varias lenguas, la traducción planteará problemas innumerables y cuyo tratamiento resulta manifiestamente arduo; pero esos mismos problemas proliferan, aunque disimulados o relegados por la tradición, en el interior de una sola lengua. El modelo "emisor a receptor", que actualiza todo proceso semiológico y semántico, es ontológicamente equivalente al modelo "lengua-fuente a lengua-receptora", empleado en la teoría de la traducción. En ambos esquemas existe "en medio" una operación de desciframiento o descodificación. (Steiner, 2001: 69).

Para Steiner, «dentro o entre las lenguas, la comunicación bumana es una traducción» (Steiner, 2001: 69, cursiva original). Su explicación de la comunicación como traducción puede ser interpretada sobre la base de la analogía: el receptor obtiene una interpretación del texto que intenta sea análoga a la construcción semántica elaborada por el productor, por el autor.

La consideración de la traducción como interpretación es clave para la explicación de su función como actividad comunicativa. La traducción implica la realización de interpretación y de transferencia, como corresponde a la interpretación transitiva, que se proyecta en una creación textual consistente en una transformación translingüística del texto origen en el texto traducción y en su transferencia comunicativa a la comunidad receptora y, dentro de esta, a los receptores de ese texto. De la dimensión interpretativa de la traducción se ha ocupado el teórico de la hermenéutica Emilio Betti, para quien la traducción es una de las formas de la interpretación en función reproductiva o representativa, junto con la crítica literaria, la representación teatral o la ejecución de obras musicales a partir de sus partituras (Betti, 1975: 40-55). Por su parte, Lubomír Doležel considera que la traducción es una forma de transducción, que es la interpretación, transformación y transmisión de los textos (Doležel, 
1986: 28 y ss.; 1990: 167-175): en la traducción se produce la interpretación de un texto, su transformación en otro texto y la trasmisión de este. Stefano Arduini ofrece en su reciente libro Tradurioni in cerca di un originale. La Bibblia e i suoi traduttori (Arduini, 2021) una reflexión sobre la interpretación como hermenéutica y la traducción, dando cuenta de la complejidad de la relación entre ambas:

Rovesciando la prospettiva tradizionale, non è la traduzione che è un tipo di ermeneutica, ma è l'ermeneutica che agisce come una sorta di traduzione. Ogni atto ermeneutico è un tipo di traduzione nella misura in cui pone in relazione un'estraneità con un soggetto. Tale estraneità può essere rappresentata da un individuo che non parla la nostra lingua o da un testo, scritto o orale, che non capiamo. La traduzione è dunque all'origine perché la questione non è comunicare ma comprendersi e trovare nell'altro qualcuno che ci corrisponda. La comunicazione è vuota se non passa attraverso una relazione che ci traduce, ci porta fuori della soggetività e solo così svela la nostra identità. (Arduini, 2021: 61-62).

La traducción interpretativa de la realidad extraña y del propio sujeto es, por tanto, una forma de búsqueda y hallazgo en la reflexividad y en la alteridad que nos proyecta fuera de nosotros mismos y hace posible la comunicación. La interpretación se da como traducción, con la implicación de la subjetividad y la alteridad. Es de este modo como se produce la mediación, que es una conexión en el hecho comunicativo, en el cual une a quienes comunican en el ámbito de ese hecho.

Sin la mediación comunicativa que es la traducción, la comunicación entre los seres humanos se vería afectada gravemente por la distancia entre la lengua del texto y los conocimientos de lenguas de una parte de los receptores. La aportación de la traducción en general, tanto la no literaria como la literaria, a la sociedad tiene un valor extraordinario en tanto en cuanto hace posible que se produzca la comunicación y facilita su desarrollo.

2. TRADUCCIÓN Y LITERATURA. ASPECTOS DE LA TRADUCCIÓN LITERARIA. LA CONEXIÓN CON LA LITERATURA COMPARADA.

Si la traducción es imprescindible en la comunicación que tiene lugar en la sociedad, por su utilidad en el ámbito jurídico, en el económico, en el periodístico, en el de los medios audiovisuales, en el sanitario, etc., no lo es menos en la literatura. La producción literaria es proyectada desde las lenguas originales de las obras a otras lenguas por medio de las traducciones. Es la traducción uno de los procesos comunicativos más 
activos en la sociedad e impulsa la extensión de la literatura a través de las fronteras, más allá de las fronteras, ampliando el conjunto de receptores de las obras literarias.

La traducción literaria es a la vez interpretación y creación. Su dimensión interpretativa está dirigida a su dimensión poiética o creativa, dimensión en la que es producido el texto meta o texto traducción, para lo cual es necesaria la interpretación minuciosa del texto de partida. El traductor lleva a cabo esta interpretación como lector de segundo conocimiento de la obra literaria, de acuerdo con el planteamiento de Dámaso Alonso, es decir, como lector culto que produce un texto crítico a partir del texto literario al que ha accedido interpretativamente como el lector del primer conocimiento de la obra literaria, como un lector plenamente implicado en su lectura (Alonso, 1981: 38-39, 203). Dámaso Alonso explica:

Ese otro ser excepcional, el crítico, no sólo tiene una poderosa intensidad de impresión, sino que reacciona, en general, ante todas las intuiciones creativas, y la intensidad de impresión debe corresponderse en él con la capacidad expresiva de los creadores, de los poetas. La lectura debe suscitarle al crítico profundas y nítidas intuiciones totalizadoras de la obra. Es el crítico, ante todo, un no vulgar, un maravilloso aparato registrador, de delicada precisión y generosa amplitud. (Alonso,1981: 203).

La implicación interpretativa del traductor es equivalente a la del lector del segundo conocimiento de la obra literaria, el crítico literario. En coherencia con la visión que George Steiner tiene de la traducción, Claudio Guillén ha escrito que el traductor es «en ciertos casos, un crítico minucioso, que aclara y nos ayuda a entender mejor las palabras remotas» (Guillén, 2005: 324). El crítico literario y el traductor literario comparten, pues, una función interpretativa sin la cual no sería posible la comprensión exhaustiva y el desentrañamiento del texto original, y, por tanto, tampoco la producción del texto de crítica literaria y la del texto traducción, que son consecuencia de esa interpretación y de su proyección comunicativa de carácter transitivo. Es de gran interés la relación entre traductor y crítico literario, que responde a la vocación interpretativa de ambos, como sucede en la relación que existe entre la función del rétor y la del crítico literario, que permite que aquél asuma la función del crítico (Chico Rico, 2021).

La traducción de un texto literario mantiene la literariedad, al ser resultado de traducir un texto que posee dicha cualidad (Albaladejo, 2005). La analogía entre el texto de partida y el texto traducción incluye el hecho de que ambos posean literariedad: tan literario es el texto traducción como el texto de partida. Para ello, el traductor literario 
tiene una importante tarea, la de conseguir un texto traducción que contenga en la medida de lo posible los rasgos de literariedad del original, con las dificultades que ello ofrece, en gran medida, aunque no únicamente, en el nivel fonofonológico en la traducción de obras en verso, en las que tanta importancia tienen el metro, el ritmo y la rima, como ha estudiado Esteban Torre (1994). La persistencia de la literariedad del texto de partida en el texto traducción se produce como proyección en este de las características de aquel y está guiada por la interpretación en función representativa o reproductiva de Emilio Betti: el texto traducción representa al texto de partida, a la obra original, de la cual es una reproducción en otra lengua (Betti, 1975: 50-51). Así, si un lector lee una determinada obra literaria en traducción, lee esa obra literaria. Ciertamente, para para que el texto traducción sea representación del texto de partida, la traducción de este debe ser no solo correcta, sino plenamente adecuada al original, lo cual no impide que haya algunas expresiones. del original que puedan ser modificadas en el texto traducción. Se trata de que este sea una representación válida del texto original, ya que, como sucede en la traducción de la poesía china (Graham, 1981; van Crevel, Klein, eds., 2019), puede haber aspectos que no queden plasmados en la traducción o cuya reproducción presente dificultad extrema, pero que, sin embargo, se intenta que sean re-creados en la traducción.

La proyección de la literariedad del texto de lengua de partida en el texto de lengua de llegada supone una actividad lingüístico-artística y comunicativa con una fuerte implicación poiética, creativa. Para José Ortega y Gasset, la traducción es un género literario (Ortega y Gasset, 1964: 449); ello, no obstante, no impide que la traducción mantenga las características del género o subgénero literario al que pertenece la obra original. La mencionada proyección, por la que los rasgos del texto original son reproducidos en el texto traducción, no excluye la intervención del traductor con el fin de mantener la dimensión representativa de base analógica en su traducción en relación con el texto de partida (Albaladejo, 2001; 2004). En la traducción literaria es posible la interferencia comunicativa del traductor en su recreación de expresiones o aspectos del texto de partida, que pueden suponer un enriquecimiento creativo de la obra en tanto en cuanto su traducción contribuye a su introducción en una lengua y en una cultura diferentes de aquellas en las que se produjo su creación. Puesto que el lenguaje literario responde a una práctica sistemática de la excepción comunicativa, como ha explicado Antonio García Berrio (1994: 81-97), la traducción literaria no es ajena a dicha práctica 
(Albaladejo, 2004: 5-9; Albaladejo, Chico Rico, 2018: 119-120), en función de la analogía entre el texto de partida y el texto traducción y, por tanto, de la correspondencia entre el lenguaje literario de ambos textos. Mientras que en la traducción no literaria las interferencias comunicativas suelen desviar el texto traducción de su función de comunicación práctica, que tiene por analogía con la del texto original, la traducción literaria, en la que la creatividad de la traducción abre la posibilidad de una cierta diferenciación del texto traducción respecto del texto de partida, puede acoger interferencias del traductor que contribuyan a la creatividad del texto traducción y a su efectividad estético-cultural en la lengua y en la cultura de llegada. Así, el escritor italiano Carlo Emilio Gadda, en Il mondo com 'è, que es su traducción al italiano de El mundo por de dentro de Francisco de Quevedo, interviene en varias ocasiones, en una de ellas al traducir «que quisieran más pasearse» (Quevedo, 1999: 288) como «Quanto sarebbe stato preferibile andar a spasso a via Merulana»(Gadda, 1977: 54), introduciendo en el texto traducción el nombre de una conocida calle de Roma. Helena Beristáin (2000: 140) ha defendido la necesidad de evitar la fidelidad total del texto traducción al texto de partida si ello impide o distorsiona la comprensión del texto traducción. Como es bien sabido, Eugene Nida planteó la distinción en la traducción entre equivalencia formal y equivalencia dinámica, siendo, por su flexibilidad, esta última la opción que hace posible un texto traducción más cercano a la cultura a la que se incorpora este texto (Nida, Taber, 1969: 22-28).

Las intervenciones del traductor literario confirman su doble condición de receptor y de productor, su condición de lector culto y de creador, al ser intérprete del texto de partida y creador del texto traducción. El traductor lleva a cabo, por tanto, una poiesis, la del texto traducción, en la que asume la configuración textual del texto de partida, tanto en su macroestructura como en su microestructura, aunque entren en juego lenguas distintas, así como su referente, la organización textual y el estilo, a todo lo cual puede aportar su propia impronta poiética en función de su búsqueda de una representación adecuada del texto de partida por parte del texto traducción. Por tanto, la actividad a la vez interpretativa y poiética del traductor abarca la totalidad de la obra literaria, con una especial atención a la microestructura en la lengua de partida y en la lengua de llegada; el traductor se ocupa del examen del estilo del texto de partida y de la elaboración estilística del texto traducción. Para Shunqing Cao, la traducción literaria se 
caracteriza por la integración, que constituye el nivel más elevado en traducción y consiste en que se mantiene en la lengua de llegada el sabor del texto original, sin que haya en el texto traducción vestigios de extranjerización (Cao, 2013: 102). Este teórico de la literatura escribe: «'Integration' means that two languages intermingle together and form a new linguistic sign through which they express the same meaning but still keep their own unique characters. The two languages could enter the same domain of the significance of different words» (Cao, 2013: 102). La dificultad de la traducción de expresiones y también de algunas obras en su totalidad, ha hecho necesario referirse a la intraducibilidad literaria (Apter, 2006: 85-93; 2013). Pero esta intraducibilidad no implica que no exista la posibilidad de traducir, ya que la traducción literaria es posible, aunque resulte difícil cuando se presenta la intraducibilidad, por medio de la creatividad del traductor, quien, como ha explicado en su teoría de la variación (Variation Theory) Shunqing Cao (2013: 117-119), puede introducir variaciones, que son inevitables en la traducción literaria:

Due to the differences in language, culture, time, and space, it is unavoidable for translating as the way of communication between languages and cultures to have distortion and Variation. Therefore, compared with the source text, the translated text is doomed to have some variations not only in the form of language but also in the context. (Cao,2013: 130).

La traducción literaria tiene una dimensión retórica puesto que actúa perlocucionariamente sobre quienes la leen, ejerciendo un efecto convincente-persuasivo a propósito del reconocimiento del texto traducción como representación del texto de partida y, al ser resultado de esta representación, como la obra misma en otra lengua, lo cual refuerza la dimensión pragmática de la traducción literaria, situada en el ámbito general de la pragmática literaria (Albaladejo, 1992; Chico Rico, 2020b). La Retórica cultural (Albaladejo, 2013; 2016; Chico Rico, 2015; 2020a: 146-152), puesto que implica la activación de todos los componentes y aspectos de la «Rhetorica recepta» (Albaladejo, 1991: 29; Chico Rico, 2017a), en la línea del planteamiento de Antonio García Berrio de la recuperación del pensamiento histórico (García Berrio, 1984: 9, 51; Chico Rico, 2019) y por tanto de todos los componentes retóricos, aporta al estudio de la traducción literaria un instrumental para el análisis y la explicación de su retoricidad y de la aceptación cultural del texto traducción como el texto de partida transformado en un texto 
equivalente a aquel en una lengua distinta. Esta aceptación afecta al texto como totalidad: implica la aceptación del referente, la de la macroestructura y la de la microestructura como nivel retórico elocutivo, del que forma parte el estilo, tan importante retórica y literariamente (Albaladejo, 2005) en la constitución del arte de lenguaje (Chico Rico, 2017b).

Willis Barnstone, atento a la dimensión creativa del traductor, se ocupa del «translator-creator» (Barnstone, 1993: 89) y se refiere a la traducción como un «double art» puesto que el texto traducción es resultado de la creación del autor del texto de partida, pero también de la actividad creativa del traductor, que puede considerarse como una re-creación. Barnstone ofrece la siguiente explicación:

The source text has one author - if there is ever an initial source. The translation, however, has at least two. For this reason, for the doubleness, perhaps the duplicity of the translation venture, I think of translation always as a "double art." The word double refers not only to the art invested in both source and target texts, but more significant, to the collaboration of two (three, four) artists, who have joined their arts and who, by the mediation of changing languages, have produced in the new work a double art. (Barnstone,1993: 88).

Esta duplicidad se da claramente en la traducción de poesía llevada a cabo por poetas, como es la traducción de la poesía de Friedrich Hölderlin por Luis Cernuda, como ha estudiado Javier Adrada de la Torre (2021), pero también está presente en la traducción que realiza quien, sin ser poeta, tiene una actitud poética y elabora una escritura propia de poeta en su traducción, en su actividad poiética en la elaboración del texto traducción.

Margaret Rogers plantea la cuestión de la frontera entre la traducción literaria y la traducción no literaria en varios aspectos y características, como la voluntad de innovación léxica y las implicaciones culturales en relación con el lector que se dan en la traducción literaria y en otras clases de traducción (Rogers, 2019: 155), como los «crossovers», fusiones o cruces terminológicos, entre traducciones de textos no literarios, textos literarios y textos sagrados (Rogers, 2019: 160-161) o como la versatilidad de quienes traducen en el ámbito de la traducción literaria y en el de la traducción no literaria (Rogers, 2019: 164). La frontera estaría situada entre los textos literarios y no literarios, más que en la actividad de traducción, si bien los textos de llegada reproducen los rasgos de los textos de partida que fundamentan su literariedad. Se debe tener en cuenta también que en el caso de algunas obras la frontera entre texto literario y no literario no está 
marcada, como sucede en In Cold Blood de Truman Capote, en Anatomía de un instante de Javier Cercas o en L'ordre du jour de Éric Vuillard.

La traducción literaria está estrechamente relacionada con la literatura comparada, como también lo está con la teoría literaria. Tanto la actividad de traducción como su análisis, su explicación y, en definitiva, su estudio permite evidenciar cuestiones, problemas y aspectos a propósito de los cuales son de gran interés las perspectivas y las contribuciones teórico-literarias, crítico-literarias y comparatistas. Para Marina Guglielmi (2002), la implicación de la traducción en la interculturalidad es clave para su conexión con la literatura comparada:

Para poder comprender el papel que la traducción desempeña en el comparatismo actual es necesario, de hecho, poder considerar en perspectiva el papel que ésta ha desempeñado en la historia de la literatura a partir de su aproximación más tradicional, la nacional, y de su superación hacia una dimensión supranacional e intercultural. (Guglielmi, 2002: 313).

La traducción que en el siglo III a. C. Livio Andrónico hizo del griego al latín de la Odisea de Homero es un caso paradigmático de las relaciones interculturales impulsadas por la traducción, que actúa como puente entre lenguas, literaturas y culturas. Estas relaciones tienen una implicación en la conexión entre literaturas y en las aportaciones que las traducciones pueden generar para la literatura de llegada, que resulta enriquecida por aquellas. La literatura latina debe mucho a las traducciones de obras griegas. La interculturalidad se ha fundamentado conceptual y epistemológicamente en tiempos más bien recientes, lo cual no impide que haya funcionado históricamente sobre la base de las relaciones entre lenguas, literaturas y culturas. En su recorrido histórico la interculturalidad se ha consolidado como característica de la traducción literaria y actualmente es clave a propósito de la relación entre literatura comparada y traducción. Quien traduce obras literarias compara la literatura y la tradición literaria en las que está situada la obra que traduce y la literatura o las literaturas asociadas a la lengua de llegada y las tradiciones literarias correspondientes, y también compara la cultura de partida y la cultura de llegada, desde una perspectiva intercultural y transcultural, que tenga en cuenta las dos culturas entre las que se encuentra la traducción y que cree un puente entre ambas culturas por medio de construcciones literarias y culturales compartidas. En esta línea, Ute Barbara Schilly (2003) ha estudiado la traducción como comunicación intercultural 
a propósito de las traducciones alemanas de la obra de Miguel Delibes, centrándose en Cinco horas con Mario y esta obra en alemán, Fünf Stunden mit Mario.

La comparación tiene en la traducción literaria un amplio campo de actuación. El traductor literario lleva a cabo una comparación continuada entre el texto de partida y el texto traducción que está elaborando. La traducción literaria exige una constante comparación entre lenguas, literaturas y culturas, que se concreta en la comparación entre el texto objeto de traducción y el resultado de esta, con la peculiaridad de que la comparación se hace en cada momento y en cada paso del proceso de traducción, además de hacerla cuando se ha completado la redacción del texto resultante de la traducción, que siempre debe ser sometido a comprobaciones analíticas de su validez en la cultura de llegada como traducción de la obra original.

Es importante considerar que, cuando de una obra se hace una traducción, es habitual que el traductor tenga en cuenta las traducciones anteriores que se han hecho de esa obra a la lengua de llegada a la que está traduciendo (e incluso las traducciones a otras lenguas) con el fin de resolver del mismo modo o de un modo diferente los puntos problemáticos que encuentra en el traducir, así como otros aspectos de su actividad de traducción. El traductor compara sus soluciones con las aportadas por anteriores traducciones de la obra que traduce. Por otro lado, la lectura y el análisis de las diferentes traducciones que existen de una obra literaria son actividades interpretativas necesariamente basadas en la comparación. La crítica literaria en relación con la traducción puede consistir en el análisis de la traducción de una obra, pero también puede implicar en determinados casos un análisis crítico comparado al contrastar diversas traducciones de una obra a una lengua, siendo también posible la comparación entre traducciones de una misma obra a distintas lenguas.

El análisis interdiscursivo, que ha sido propuesto en el ámbito de la literatura comparada (Albaladejo, 2008), puesto que se ocupa del análisis comparado de textos o discursos concretos literarios y no literarios, de los géneros literarios y otras clases de textos o discursos y también de aspectos de las disciplinas que estudian los textos o discursos, incluye el estudio comparado de las obras originales y las obras traducidas, así como el de las traducciones de diferentes obras a una misma lengua o a varias lenguas.

La literatura traducida está constituida por el amplísimo conjunto de obras de diferentes literaturas que han sido traducidas a diferentes lenguas y pueden tener una 
posición central o una posición periférica en las literaturas y las culturas a las que se incorporan como traducciones, dependiendo de circunstancias históricas y de poder cultural (Even-Zohar, 1990: 49-50). Como ha explicado José Lambert, la literatura traducida implica la existencia de una importación de obras desde las literaturas de partida a las literaturas de llegada (Lambert, 1980), con la consiguiente influencia en la configuración de estas literaturas o de determinados periodos históricos y tendencias de las mismas. La traducción literaria contribuye a consolidar la literatura de la lengua de la que se traduce y, a la vez, la literatura de la lengua a la que se traduce. A la lengua de partida y a la lengua de llegada les ofrece la traducción una importante oportunidad de superar la desigualdad entre lenguas y culturas y la asimetría que dicha desigualdad puede producir en un mundo como el actual en el que existen múltiples interrelaciones como consecuencia de la globalización (Vidal Claramonte, 2010; 2018). Que se traduzcan obras literarias escritas en una determinada lengua y situadas en una determinada cultura es un apoyo para dicha lengua y dicha cultura. Por otro lado, el que se hagan traducciones de obras literarias a una lengua y el que estas obras lleguen a situarse en otro espacio literario y cultural, sin duda, enriquece la lengua, la literatura y la cultura de llegada.

Stefano Arduini y Siri Nergaard han propuesto la expresión y el concepto de «Post-translation studies» para referirse a la evolución de la traducción desde una delimitación metodológica hasta una apertura a otros campos del conocimiento en los que se reflexiona y se teoriza sobre la traducción (Arduini, Nergaard, 2011):

\footnotetext{
We imagine a sort of new era that could be termed post-translation studies, where translation is viewed as fundamentally transdisciplinary, mobile, and open ended. The "post" here recognizes a fact and a conviction: new and enriching thinking on translation must take place outside the traditional discipline of translation studies. The time is past when we can maintain the usual borders of translation studies, just as the time is past when in a more general way we can close the borders of certain disciplines and exclude translation discourse from entering their intellectual space. We are convinced that today - at least in the humanities but surely in principle for all academic fields - exchange and dynamic discourse are fundamental. (Arduini, Nergaard, 2011: $8-9)$.
}

Los estudios de la postraducción tienen una vocación transdisciplinar que lleva a plantear amplias perspectivas interrelacionadas, en las que se encuentran las aportaciones de la teoría de la traducción a otros campos del conocimiento y asimismo las aportaciones de estos otros campos a la traducción. Edwin Gentzler (2017) ha profundizado en la postraducción en un estudio de este concepto en el que está activamente presente la 
reescritura, así hace referencia a «post-translation rewritings that continue to shape the respective receiving cultures today» (Gentzler, 2017: 222).

La era de la postraducción a la que hacen referencia Arduini y Nergaard acoge el estudio de las contribuciones de la traducción a las culturas, a los espacios linguiísticos y a los espacios literarios a los que han llegado los textos traducidos, incluyéndose en ese estudio el análisis y la explicación de nuevos textos que existen gracias a que han podido generarse a partir de las traducciones que se han incorporado al espacio cultural receptor en el que son creados.

Puede establecerse una relación entre la postraducción y la transducción planteada por Doležel, en la que las cadenas de transmisión tienen una importante función: «Literary texts constantly transcend the boundary of individual speech acts and enter into complex chains of transmission»(Doležel, 1990: 167). La postraducción puede dar lugar a diversos textos conectados con el texto original y sus traducciones (y con el texto original a través de sus traducciones). La perspectiva comparada es imprescindible en la postraducción, como lo es en la transducción: los diferentes textos que son producidos en la reescritura, especialmente en los casos de reescrituras encadenadas en una relación de sucesividad, pero también en los casos de reescrituras paralelas, no pueden ser analizados y explicados sin someterlos a un proceso de comparación en el que se tengan en cuenta la semejanza y la diferencia (también la variación), la originalidad y el efecto estético.

La traducción literaria tiene relación con la traducción intersemiótica al haber obras literarias que son resultado de la interpretación de obras pictóricas, como el poema El Cristo de Velázquez de Miguel de Unamuno, y obras musicales creadas a partir de obras literarias, como la antes citada sinfonía Harold en Italie de Berlioz, junto a otras posibilidades de relaciones intersemióticas. Se trata de una relación que se sitúa en una dimensión de literatura comparada en tanto en cuanto son comparadas las obras literarias y las de otras artes, entre las que se realiza una traducción intersemiótica. Es la teoría de la multimodalidad (Boria, Carreres, Noriega-Sánchez, Tomalin, eds., 2020), centrada en el modo más que en el signo, la que responde a la necesidad de tener en cuenta en la traducción el paso de unos modos de construcción artística a otros (Kaindl, 2020: 49-50), la transformación modal de las obras, con la necesaria atención a la literatura, implicando una perspectiva comparada. Sin embargo, el concepto de signo no es abandonado, ya que su impronta epistemológica como unidad semiótica es muy sólida y, por tanto, se 
mantiene como fundamento de las relaciones intersemióticas y multimodales en la traducción (Campbell, Vidal, eds., 2019). Las perspectivas metodológicas que ofrecen el signo y el modo no son incompatibles, sino que son complementarias.

Es indudable la contribución de la traducción a la configuración, con distintos grados de cohesión, de espacios transnacionales (Ramazani, 2009; Ashcroft, 2010: 22; Valdivia, 2018: 177; Albaladejo, 2019: 397-398), espacios que superan los límites de las distintas naciones que los componen y que en su conjunto los engloban, como es el caso del espacio europeo. En su libro Poétique du traduire, Henri Meschonnic escribe: «L'Europe est née de la traduction et dans la traduction» (Meschonnic, 1999: 32). Desde las traducciones de obras de la literatura griega al latín hasta la actual globalización literaria de Europa, la traducción literaria desempeña una función clave en la construcción y la consolidación, cada vez más intensa, del espacio cultural europeo, en el que actúan, por ejemplo, las traducciones de las lenguas escandinavas a otras lenguas europeas de las novelas negras nórdicas o las traducciones a otras lenguas europeas de las obras de José Saramago, de Joanne K. Rowling, de Fernando Aramburu o de Elfriede Jelinek. Lieven D’hulst plantea la función de la traducción entre las distintas lenguas europeas como una interconexión por comunicación traductológica (D’hulst, 2013: 388) y se pregunta «¿Han contribuido progresivamente las traducciones a la aparición del concepto de "Europa"?» (D’hulst, 2013: 395), para más adelante responder: «En general, no es fácil conocer hasta qué punto la traducción ha intervenido en la "construcción" de Europa, pero por lo menos nos muestra que debemos "repensar" Europa partiendo de un conjunto de perspectivas relacionales» (D'hulst, 2013: 399). La traducción es indudablemente una forma muy dinámica de relación entre lenguas, culturas, literaturas y también entre espacios nacionales y contribuye de un modo importante a la dimensión transnacional de los elementos o componentes que relaciona. Como David Amezcua ha explicado, la traducción es un tópos (Amezcua, 2016). La traducción literaria y la propia existencia de una literatura europea de carácter transnacional que engloba distintas literaturas nacionales contribuyen a fundamentar la configuración europea en el ámbito cultural, pero también en el político y en el social: sería difícil concebir la Unión Europea y las diferentes fases que permitieron llegar a su constitución y a su actual configuración sin el papel de la literatura, la cultura y, por supuesto, la traducción en la cohesión europea (Albaladejo, 2019: 398-399), incluso más allá de la Unión Europea y a pesar de 
desencuentros como el que representa el Brexit, ya que el Reino Unido es, sin ninguna duda, uno de los componentes del espacio cultural y literario europeo.

La traducción literaria contribuye a la literatura comparada también por el hecho de que facilita la lectura de obras a quienes no conocen la lengua original en la que están escritas, al hacer posible la lectura en una lengua conocida por el lector. La literatura traducida desempeña un papel importante en la literatura del mundo o literatura universal. La traducción hace posible la difusión y, por tanto, el conocimiento de las obras literarias más allá de los límites linguiísticos de una cultura y de una literatura. Cuando, en la conversación mantenida por Johann Wolfgang von Goethe y Johann Peter Eckermann el 31 de enero de 1827, en la que el autor de Faust habla de la Weltliteratur tras comentar a Eckermann que está leyendo una novela china, y la está leyendo en traducción. El concepto de Weltliteratur es muy importante para la literatura comparada, al ofrecer una visión global de la literatura como creación de distintas culturas, de distintas lenguas y de distintos pueblos o naciones. Y para la Weltliteratur es clave la actividad de la traducción literaria. Para el canon (Bloom, 1995; Pozuelo Yvancos, Aradra Sánchez, 2000; Pozuelo Yvancos, 2009; Scheck, 2019; Pozuelo Yvancos, Rodríguez Alonso, 2021) es también importante la traducción literaria, es gracias a ella como las obras literarias de los diferentes cánones (el canon occidental, el canon europeo, el canon hispánico, etc.) se van configurando, tanto por las lecturas de las obras en lengua original como por las lecturas en traducciones, las cuales refuerzan la posición canónica de las obras al llevarlas a amplios espacios lingüísticos y culturales.

\section{ConClusión.}

La traducción es una actividad necesaria para la literatura. Contribuye al conocimiento de las obras literarias más allá de los límites de las distintas lenguas, influye en la creación de nuevas obras literarias, es una conexión con la historia de las literaturas y a la vez una proyección en el futuro de estas. La traducción exige profundizar interpretativamente en la obra, exprimir su significado o sus significados y hace posible e impulsa la creación de nuevas obras en lenguas distintas de la de la obra original. La traducción facilita el paso de las obras de unas culturas a otras y las correspondientes 
fructificaciones que se producen en las culturas de acogida gracias a las obras que entran en estas por la traducción.

La analogía, planteada por Aristóteles en la Poética a propósito de la metáfora (Aristóteles, 1974: 1457b9-33), ofrece una alta capacidad explicativa para el análisis de las sustituciones discursivas, no solo la metafórica, sino también otras como la alegoría y la traducción. En la metáfora, la expresión presente sustituye a la expresión ausente y es el productor lingüístico el que da, en su proceso creativo, el paso de la ausente a la presente, construyendo el texto de modo que el que el receptor, en su interpretación, dé el paso de la presente a la ausente. Ambas expresiones mantienen una relación basada en la semejanza y en la diferencia, es la semejanza la que las relaciona y la diferencia la que hace que sean dos expresiones distintas, sustituyendo una a la otra, la presente a la ausente. La idea de transferencia está contenida en el nombre griego de la metáfora ( $\mu \varepsilon \tau \alpha \varphi \rho \rho \alpha ́)$, pero también en el nombre latino de este tropo (translatio, además de la adaptación latina del nombre griego: metaphora). Son once los verbos latinos que significan «traducir», como ha explicado Stefano Arduini, uno de los cuales es transferre, a partir de cuyo supino (translatum) se forma el sustantivo translatio, aunque, como explica este prestigioso especialista en traducción, vertere es el que mejor expresa la idea del traducir (Arduini, 2021: 63-72). Translatio implica transferencia, traslado, y da cuenta de la sustitución que se produce en la metáfora y también en la traducción general y en la traducción literaria. Es la analogía la que sostiene la equivalencia (formal o dinámica) entre el texto de partida y el tex to traducción, contando con que ambos poseen literariedad en la traducción literaria. La analogía no es identidad, ya que los objetos lingüísticos relacionados analógicamente son diferentes, con elementos compartidos y con elementos propios de cada uno de dichos objetos. Existe analogía entre el texto de partida y el texto traducción, funcionando el primero de ellos como texto ausente frente al texto presente, que es el texto de llegada, el texto traducción, que forma parte de la literatura traducida y es objeto de lectura por el receptor de la traducción literaria. La analogía entre el texto de partida y el texto traducción existe incluso en los casos en los que en el texto traducción han sido necesarias variaciones para superar la intraducibilidad o la difícil traducibilidad. Y es la analogía la que sostiene la función de representación de la obra literaria original que ejerce la obra literaria traducida, con todas las diferencias y variaciones que pueda tener respecto de la obra de la que es traducción. Analogía, equivalencia y representación 
se constituyen como un conjunto de conceptos que, siendo diferentes, están relacionados entre sí y permiten explicar la validez comunicativa, lingüística, literaria y cultural de la traducción literaria. La analogía hace posible la equivalencia y ambas impulsan el valor de representación de la traducción literaria. Y la comparación entre elementos lingüísticos, entre las obras y entre las literaturas y las culturas implicadas en la traducción literaria sitúa esta actividad comunicativa, interpretativa y creativa, en el ámbito de la literatura comparada con una especial relación con la interculturalidad. 


\section{BIBLIOGRAFÍA}

Adrada de la Torre, Javier (2021): Luis Cernuda y Friedrich Hölderlin: traducción, poesía y representación, Granada, Comares.

Albaladejo, Tomás (1991): Retórica, Madrid, Síntesis.

Albaladejo, Tomás (1992): «Aspectos pragmáticos y semánticos de la traducción del texto literario», en Koiné. Quaderni di Ricerca e Didattica sulla Traduzione e l'Interpretazione, II, 1-2: 179-200.

Albaladejo, Tomás (1998): «Del texto al texto. Transformación y transferencia en la comunicación literaria», en Estanislao Ramón Trives; Herminia Provencio Garrigós (eds.): Estudios de lingüística textual. Homenaje al Profesor Muñoz Cortés, Murcia, Universidad de Murcia: 31-46.

Albaladejo, Tomás (2001): «Traducción e interferencias comunicativas», en Hermēneus. Revista de Traducción e Interpretación, 3: 39-58.

Albaladejo, Tomás (2004): «Similarity and Difference in Literary Translation», en Stefano Arduini; Robert Hodgson (eds.): Similarity and Difference in Translation, New York - Rimini, Nida Institute - Guaraldi: 449-462.

Albaladejo, Tomás (2005): «Especificidad del texto literario y traducción», en Consuelo Gonzalo García; Valentín García Yebra (eds.): Manual de documentación para la traducción literaria, Madrid, Arco/Libros: 45-58.

Albaladejo, Tomás (2008): «Poética, literatura comparada y análisis interdiscursivo», en Acta Poetica, 28, 2: 245-275.

Albaladejo, Tomás (2013): «Retórica cultural, lenguaje retórico y lenguaje literario», en Tonos Digital. Revista de Estudios Filológicos, 25.

http://www.tonosdigital.es/ojs/index.php/tonos/article/view/974 (último acceso: $15 / 07 / 2021)$.

Albaladejo, Tomás (2016): «Cultural Rhetoric: Foundations and Perspectives», en Ars Rhetorica, 3, 1: 16-28.

DOI: https://doi.org/10.17380/rr2016.1.2 (último acceso: 15/07/2021). 
Albaladejo, Tomás (2019): «European Crisis, Fragmentation and Cohesion: The Contribution of Ectopic Literature to Europeanness», en Journal of European Studies, 49, 3-4: 394-409.

Albaladejo, Tomás; Francisco Chico Rico (2018): «Translation, style and poetics», en Harding, Carbonell Cortés (eds.) (2018): 115-133.

Alonso, Dámaso (1981): Poesía española. Ensayo de métodos y límites estilísticos, Madrid, Gredos, $5^{\mathrm{a}}$ ed., $3^{\mathrm{a}}$ reimpr.

Amezcua Gómez, David (2016): «Literatura ectópica: la traducción como topos en Out of Place de Edward Said», en Revista Academica liLETRAd, 2: 709-716.

Apter, Emily (2006): The Translation Zone. A New Comparative Literature, Princeton, Princeton University Press.

Apter, Emily (2013): Against World Literature. On the Politics of Untranslatability, London - New York, Verso.

Arduini, Stefano (2021): Traduzioni in cerca di un originale. La Bibbia e i suoi traduttori, Milano, Jaca Book.

Arduini, Stefano; Siri Nergaard (2011): «Translation: A New Paradigm», en Translation. A Transdisciplinary Journal, inaugural issue: 8-17.

Aristóteles (1974): Poética, edición trilingüe de Valentín García Yebra, Madrid, Gredos. Ashcroft, Bill (2010): «Globalization, transnation and utopia», en Walter Goebel; Saskia Schabio (eds): Locating Transnational Ideals, New York, Routledge: 13-29.

Barnstone, Willis (1993): The Poetics of Translation. History, Theory, Practice, New Haven, Yale University Press.

Beristáin, Helena (2000): «Poética, retórica y traducción literaria», en Helena Beristáin; Mauricio Beuchot (comps.): Filosofía, retórica e interpretación, México, Universidad Nacional Autónoma de México: 129-141.

Betti, Emilio (1975): Interpretación de la ley y de los actos jurídicos, traducción de José Luis de los Mozos y de los Mozos, Madrid, Editoriales de Derecho Reunidas.

Bloom, Harold (1995): El canon occidental. La escuela y los libros de todas las épocas, traducción de Damián Alou, Barcelona, Anagrama.

Boria, Monica; Ángeles Carreres; María Noriega-Sánchez; Marcus Tomalin (eds.) (2020): Translation and Multimodality. Beyond Words, Abingdon, Routledge. 
Campbell, Madeleine; Ricarda Vidal (eds.) (2019): Translating across Sensory and Linguistic Borders, London, Palgrave Macmillan.

Cao, Shunqing (2013): The Variation Theory of Comparative Literature, Heidelberg, Springer.

Chico Rico, Francisco (2015): «La Retórica cultural en el contexto de la Neorretórica», en Dialogía. Revista de Lingüística, Literatura y Cultura 9: 304-322. https://journals.uio.no/Dialogia/article/view/2597 (último acceso: 31/08/2021).

Chico Rico, Francisco (2017a): «Contra la crisis de la Retórica: Gregorio Mayans y Siscar (1699-1781)», en Concepción Camarero Bullón; Juan Carlos Gómez Alonso (coords.): El dominio de la realidad y la crisis del discurso. El nacimiento de la conciencia europea, Madrid, Polifemo (Colección La Corte en Europa): 423-452.

Chico Rico, Francisco (2017b): «El espacio del arte de lenguaje en la Institutio oratoria de Quintiliano», en Actio Nova. Revista de Teoría de la Literatura y Literatura Comparada 1: 1-26. https://revistas.uam.es/actionova/article/view/8669 (último acceso: 31/08/2021).

Chico Rico, Francisco (2019): «János S. Petőfi’s Linguistic and Textual Theory and the Recovery of the Historical Thinking about Rhetoric», en Margarita Borreguero Zuloaga; Luciano Vitacolonna (eds.): The Legacy of János S. Petöfi: Text Linguistics, Literary Theory and Semiotics, Newcastle upon Tyne, Cambridge Scholars Publishing: 110-131.

Chico Rico, Francisco (2020a): «Desarrollos actuales de los estudios retóricos en España: la Retórica desde la Teoría de la Literatura», Rétor. Revista de la Asociación Argentina de Retórica 10, 2: 133-164.

http://www.revistaretor.org/pdf/retor1002_chicorico.pdf (último acceso: 31/08/2021).

Chico Rico, Francisco (2020b): «Pragmática y estudios literarios», en María Victoria Escandell Vidal; José Amenós Pons; Aoife Kathleen Ahern (eds.): Pragmática, Madrid, Akal: 640-656.

Chico Rico, Francisco (2021): «Quintilian as a Literary Critic», en Marc van der Poel; Michael Edwards; James J. Murphy (eds.): The Oxford Handbook of Quintilian, Oxford, Oxford University Press: 219-235. 
D’hulst, Lieven (2013): «La traducción y su papel en las literaturas europeas. Algunas preguntas y respuestas», traducción de Marta Duyos Míguez, en César Domínguez (comp.): Literatura europea comparada, Madrid, Arco/Libros: 388-400.

Doležel, Lubomír (1986): «Semiotics of Literary Communication», en Strumenti Critici, 50, nuova serie, I, 1: 5-48.

Doležel, Lubomír (1990): Occidental Poetics. Tradition and Progress, Lincoln, University of Nebraska Press.

Eckermann, Johann Peter (2005): Conversaciones con Goethe en los últimos años de su vida, traducción de Rosa Sala Rose, Barcelona, Acantilado.

Even-Zohar, Itamar (1990): «The Position of Translated Literature within the Literary Polysystem», en Poetics Today, 11, 1: 45-51.

Gadda, Carlo Emilio (1977): Il mondo com'è, en La verita sospetta. Tre traduzioni di Carlo Emilio Gadda, Milano, Bompiani: 33-98.

García Berrio, Antonio (1984): «Retórica como ciencia de la expresividad (Presupuestos para una Retórica General)», en Estudios de Lingüística Universidad de Alicante, 2: 7-59.

DOI: https://doi.org/10.14198/ELUA1984.2.01 (último acceso: 31/08/2021).

García Berrio, Antonio (1994): Teoría de la literatura (La construcción del significado poético), Madrid, Cátedra, $2^{\mathrm{a}}$ ed. revisada y ampliada.

Gentzler, Edwin (2017): Translation and Rewriting in the Age of Post-Translation Studies, Abingdon, Routledge.

Graham, Angus Charles (1981): «The Translation of Chinese Poetry», en Poems of the Late T'ang, translated with and introduction by A. C. Graham, Hardmondsworth, Penguin Books.

Guglielmi, Maria (2002): «La traducción literaria», en Armando Gnisci (ed.): Introducción a la literatura comparada, traducción de Luigi Giuliani, Barcelona, Crítica: 291-345.

Guillén, Claudio (2005): Entre lo uno y lo diverso. Introducción a la Literatura Comparada (Ayer y hoy), Barcelona, Tusquets.

Harding, Sue-Ann; Ovidi Carbonell Cortés (eds.) (2018): The Routledge Handbook of Translation and Culture, Abingdon, Routledge. 
Jakobson, Roman (1974): «En torno a los aspectos lingüísticos de la traducción», en Roman Jakobson, Ensayos de lingüística general, traducción de Josep María Pujol y Sem Cabanes, Barcelona, Seix Barral: 67-77.

Kaindl, Klaus (2020): «A theoretical framework for a multimodal conception of translation», en Boria, Carreres, Noriega-Sánchez, Tomalin (eds.) (2020): 49-70.

Lambert, José (1980): «Production, tradition et importation: une clef pour la description de la littérature et de la littérature en traduction», en Canadian Review of Comparative Literature / Revue Canadienne de Littérature Comparée, 7: 246-252. Meschonnic, Henri (1999): Poétique du traduire, Paris, Verdier.

Nida, Eugene A.; Charles R. Taber (1969): The Theory and Practice of Translation, Leiden, Brill.

Ortega y Gasset, José (1964): «Miseria y esplendor de la traducción», en José Ortega y Gasset: Obras completas, Madrid, Revista de Occidente, Vol. V, 6ª ed.: 431-452.

Pozuelo Yvancos, José María (2009): «Razones para un canon hispánico», en Signa, 18: $87-97$.

DOI: https://doi.org/10.5944/signa.vol18.2009.6200 (último acceso: 31/08/2021).

Pozuelo Yvancos, José María; Rosa María Aradra Sánchez (2000): Teoría del canon y literatura española, Madrid, Cátedra.

Pozuelo Yvancos, José María; Mariángeles Rodríguez Alonso (2021): «Veinte años de teoría: Canon, pensamiento literario e historiografía», en Theory Now. Journal of Literature, Critique, and Thought, 4, 1: 6-21.

DOI: https://doi.org/10.30827/tnj.v4i1.15928 (último acceso: 10/09/2021).

Quevedo, Francisco de (1999): Los Sueños, edición de Ignacio Arellano, Madrid, Catedra, $3^{\mathrm{a}}$ ed.

Ramazani, Jahan (2009): A Transnational Poetics, Chicago, The University of Chicago Press.

Rogers, Margaret (2019): «From binaries to borders: Literary and non-literary translation», en Helle V. Dam; Matilde Nisbeth Brøgger; Karen Korning Zethsen (eds.): Moving Boundaries in Translation Studies, Abingdon, Routledge: 151-167

Scheck, Denis (2019): Schecks Kanon: Die 100 wichtigsten Werke der Weltliteratur, München, Piper. 
Schilly, Ute Barbara (2003): Carmen spricht Deutsch. Literarische Übersetzung als interkulturelle Kommunikation am Beispiel des Werkes von Miguel Delibes, Würzburg, Königshausen und Neumann.

Steiner, George (2001): Después de Babel. Aspectos del lenguaje y la traducción, traducción de Adolfo Castañón y Aurelio Major, Madrid, Fondo de Cultura Económica, $2^{\mathrm{a}}$ ed., $1^{\mathrm{a}}$ reimpr.

Torre Serrano, Esteban (1994): Teoría de la traducción literaria, Madrid, Síntesis.

Valdivia, Pablo (2018): Spanish Literature, Crisis and Spectrality: Notes on a Haunted Canon, Zürich, LIT Verlag.

van Crevel, Maghiel; Lucas Klein (eds.) (2019): Chinese Poetry and Translation. Rights and Wrongs, Amsterdam, Amsterdam University Press.

Vidal Claramonte, María Carmen África (2010): Traducción y asimetría, Bern, Peter Lang.

Vidal Claramonte, María Carmen África (2018): «Power», en Harding, Carbonell Cortés (eds.) (2018): 79-96. 


\section{SOBRE EL AUTOR}

\section{Tomás Albaladejo}

Es Catedrático de Teoría de la Literatura y Literatura Comparada en la Universidad Autónoma de Madrid, de cuya Facultad de Filosofía y Letras ha sido Decano. Licenciado en Filosofía y Letras por la Universidad de Murcia. Doctor en Letras Modernas por la Universidad de Bolonia como Colegial del Real Colegio de España en Bolonia. Ha sido Ayudante en las Universidades de Málaga y Murcia, Profesor Titular en la Universidad de Alicante y Catedrático en la Universidad de Valladolid. Es Profesor Honorario de la Universidad de Nottingham y de la Universidad Nacional Mayor de San Marcos de Lima. Ha realizado estancias en las Universidades de Bielefeld, Tours, Nottingham y Oxford. Sus líneas de investigación: lenguaje literario, retórica, narrativa, poesía, teoría de la traducción literaria, literatura digital, discurso político, literatura ectópica. Algunas de sus últimas publicaciones: «Cultural Rhetoric. Foundations and perspectives», «European crisis, fragmentation and cohesion: the contribution of ectopic literature to Europeanness», «Writing memory in conflict and post-conflict: Hernán Valdés' Tejas Verdes», «Analogía y configuración discursiva en la narrativa breve de Miguel Delibes: "La conferencia", "El sol" y "El patio de vecindad”», «Utopía en el Quijote. El discurso de la Edad de Oro».

\section{Contact information:}

Departamento de Lingüística General, Lógica y Filosofía de la Ciencia, Lenguas Modernas, Teoría de la Literatura y Literatura Comparada y Estudios de Asia Oriental

Facultad de Filosofía y Letras

Universidad Autónoma de Madrid

Calle Francisco Tomás y Valiente, 1

Ciudad Universitaria de Cantoblanco

E-28049 Madrid

Teléfono: $(+34) 914975537$

Fax: (+34)914974498

Correo-e: tomas.albaladejo@uam.es 